\title{
Co-construction of Disaster-stricken Areas from the Perspective of Multiple Governance
}

\author{
Guo Jiao \\ Southwest Jiaotong University \\ School of Public Administration and Political Law \\ Chengdu, Sichuan
}

\begin{abstract}
In the 10-year post-disaster reconstruction process after Wenchuan earthquake, a mechanism for post-disaster reconstruction involving government, social organizations, enterprises and individuals has been formed. The purpose of this paper is to provide new ideas for exploring emergency management by summarizing the operation mechanism and effectiveness of this mechanism in the process of post-disaster reconstruction. This paper sums up the development and changes of disaster areas in the 10 years by case study analysis, and draws a conclusion that the multiple-dimensional collaborative participation mechanism has strong strength with fast rhythm and high efficiency. Relatively speaking, this study not only provides a reference for better promoting the high-quality development of disaster areas, but also explores the new development of emergency management mechanism.
\end{abstract}

Keywords-Multiple-governance; Multiple-participation; Co-construction of disaster areas; Contingency management

\section{THE NeCESSity OF MUltiPle GOVERNANCE IN DISASTER-STRICKEN AREAS}

Multivariate governance refers to the mechanism of cooperation and Co-governance of multiple subjects, as opposed to single authoritative governance. In the reconstruction system of disaster areas, the perspective of multiple-governance as follows: diversification of participants in reconstruction, multiple-channel of reconstruction financing, multiple-dimensional supervision of reconstruction process and decision-making and reconstruction planning. Nowadays, new challenges have been posed to the government and the single governance of the government has also been questioned due to the frequent occurrence of public crises such as earthquake disasters. The 10 -year reconstruction process has brought a New situation of the 5.12 disaster area. The reasons also make us realize the importance of participation of social organizations, markets and disaster-stricken people in disaster reduction and relief. In the new era, the new social governance pattern of co-construction has important guiding significance for promoting the disaster reduction and relief system of public crises. Based on the destructive nature of disasters, there is a theoretical and practical necessity for multiple-governance in disaster areas.

\section{A. Theoretical basis}

Post-disaster reconstruction is not only recovery, but also development. The new pattern of multiple-governance involves the common interests of multiple-participants. It can better grasp the "chassis" of governance, and more firmly stand on the "ladder" of development. Based on the "stakeholder" theory, it's governance objectives are consistent and the governance structure is the same and the governance power is coordinated.

\section{B. Practical experience}

Post-disaster reconstruction is a complex practical project, including infrastructure, institutional system and other aspects, which needs to be supported by a synergistic dynamic mechanism. The joint participation of government-led, social organizations, enterprises and individuals is conducive to the formation of this mechanism and plays an important practical guiding role in post-disaster reconstruction.

1) Difficulties in reconstruction: The disaster environment is more complex in Earthquake-stricken areas because those areas also have the instability of disaster.

In addition, the sudden nature of disasters has caused the victims suffered serious psychological trauma in a short period of time, with serious pessimism and difficulty in psychological reconstruction; at the same time, disasters have damaged the original social relations and also need to realize the process of social readjustment after the disaster reconstruction. The original family, community and other social network covers a wide range of social relations. The complex reconstruction of social relations and other factors have posed enormous challenges to the reconstruction of disaster areas. Facing the enormous pressure of short time to complete those heavy task of realizing the sustainable development of economy and society in disaster-stricken areas if only relying on the single force of the government. therefore, the development of non-governmental organizations in China has begun to take shape, as an effective way to assist the government to shoulder the heavy task of reconstruction. under this situation, a variety of forces Cooperation is imperative and the joint involvement 
of various social subjects is inevitable in order to achieve the recovery and revitalization of disaster-stricken areas.

2) Embodiment of public value: Public crises such as the Wenchuan earthquake concern the common interests of the whole people.

The government, the market, the society and the people cannot ignore their personal interests. Therefore, the participation of various forces is realistic urgency. In the actual reconstruction process, top-down government relief and bottom-up civil society relief are all needed. As the core force of the whole reconstruction process, the people run through the whole reconstruction process and acquired the direct beneficiaries of the reconstruction results. Based on the reflection of their own values, multiple-governance in disaster areas is inevitable.

3) Limitations of single governance of traditional governments: In the traditional disaster management system, the government plays an absolute leading role in the whole disaster relief system as a direct actor.

In this process [1], a series of problems, such as the outbreak of disasters and instability, make the government fail to cope with such incidents. Or the government is unable to support the human, material, and financial resources needed for disaster reduction and relief. At the same time, the destruction of disasters causes more economic and social losses. The single government's monopoly causes extremely serious financial crisis, and the supply also exceeds demand, which hinders the response to the crisis. The timeliness of machine management poses a great challenge to the rigid operation system of the government.

\section{RESEARCH ON THE MECHANISM OF MULTIPLE-PARTY COOPERATION AND CO-CONSTRUCTION IN DISASTER AREAS}

The construction of the post-disaster reconstruction system under the multiple-governance mode includes three aspects: improving the structure of the governance subject, clarifying the rights and responsibilities of the governance subject and establishing the guarantee mechanism of cooperative governance [2]. To ensure the smooth implementation of the post-disaster co-modeling mode, it embodies four guarantees: multiple-supply of public services, multiple-financing, effective supervision and rational decision-making.

\section{A. Multiple-subject structure}

Post-disaster reconstruction is the key link of the whole disaster relief system. It has a long cycle and a heavy task. All forces must be mobilized in combination. The main way of participation is as follows: one main body (government) is pluralistic (society, market and individual):

1) Government-overall leadership: Government departments, as public service providers, bear the main responsibility for disaster reduction and relief, and are the leading force for post-disaster reconstruction. The government uses its public power and public resources to grasp the overall situation of post-disaster reconstruction, and is the main planner and responsible person for the reconstruction project. Its form of participation is as follows: "policy first + guarantee second".
2) Society - participation and synergy: Following the Wenchuan Earthquake, non-governmental organizations also took active action to work together for post-disaster reconstruction, which is an important complementary force for post-disaster reconstruction. The main forms of participation as follows: reserve reinforcement, effective assistance and resource supplement [3].

3) Market--intervention and promotion: Social forces play an increasingly important role in post-disaster reconstruction. At the same time, enterprises as the main actors of the market intervene in the post-disaster road. It follows the principle of "scientific relief, orderly participation", more rational intervention adjust the market through its own advantages and more efficient to promote the smooth progress of post-disaster reconstruction.

4) People--Core Force: As the beneficiaries of reconstruction, victims also have the right and obligation to participate in the reconstruction team. In the whole reconstruction process, the people in the disaster area, as the "main force", responded positively to other participants, joined the reconstruction team with a huge number of advantages as the main force of reconstruction, and played their own public welfare. Spiritual and personal values.

\section{B. Power-responsibility relationship among subjects}

The reconstruction of disaster area is a complex project. it is necessary to build a reasonable and effective multiple-participation system based on its long-term stability and sustainable development. Coordination and overall planning of the relations among the multiple-participants is the key and guarantee of orderly and effective co-construction.

1) The relationship between government and market: As the "two hands" of the socialist market economy, the government and the market play a key role in the development of the country and society at any time and anywhere. Disasters cover a wide range and have a great influence. visible and invisible hands must play it's role in the reconstruction process. The relationship between them follows the principle of "cooperation at different times". The government plays an important guiding role as the main supplier of public services in post-disaster reconstruction. Therefore, we must face up to the leading role of the government. However, market forces are increasingly needed to participate with the progress of reconstruction process and the passage of time. At this time, the market will play a fundamental role in the allocation of resources. The rational use of resources through market regulation drives the rapid development of reconstruction projects.

2) The relationship between government and non-governmental organizations: As the leader and reserve force, the government and non-governmental organizations play an indispensable role in the reconstruction process of disaster areas. We must deal with the synergy between the two and better serve the post-disaster reconstruction. In the process of reconstruction, the government and society follow the relationship of "incomplete cooperation". The government plans and designs the whole reconstruction process by implementing and utilizing public power, and actively 
cooperates with social organizations to join the reconstruction team to integrate and distribute reconstruction resources for a better guide the work of social organizations. At the same time, through their own advantages, social organizations play their own spirit of public welfare, avoid blind intervention, obey the guidance of the government to participate in the process of post-disaster reconstruction in an orderly manner, and supervise government departments throughout the reconstruction process, in order to promote better reconstruction of disaster areas.

\section{Guarantee mechanism}

The safeguard mechanism of multiple-dimensional and cooperative construction is an important guarantee to achieve efficient reconstruction, which is related to the overall situation. It is embodied in the various stages and key details of the reconstruction process, involving public services, reconstruction funds, supervision and implementation and decision-making links and other aspects.

1) Multiple-supply system of public service: The fundamental purpose of post-disaster reconstruction is to promote the development of the people in disaster areas. Therefore, the reconstruction of infrastructure is the first step in the reconstruction process. So how to effectively provide public services is the fundamental problem that must be solved in post-disaster reconstruction. The government-led public service supply mode is often adopted when public crisis events occur. The multiple-supply model from the perspective of multiple-governance is an innovation under the new governance pattern.

2) Reconstructing multiple-financing channels of funds: Based on the previous practical experience, most of the funds needed for post-disaster reconstruction depend on the government's financial allocation and transfer payments, which are characterized by stages and rigidity, and lack of flexibility in the use of funds. Under this scenario, based on the multiple-governance model of disaster areas, the funds needed for co-construction in disaster areas should be mobilized and participated in financing through multiple channels. Mechanisms, while allocating financial funds, actively absorb social forces to participate in them, leverage the input of social capital, and strengthen the motive mechanism of fund raising.

3) Joint efforts to achieve effective supervision: Effective supervision and management is an important guarantee mechanism for reconstruction. Faced with the huge project of reconstruction after Wenchuan disaster, we adopted a supervision pattern that combines special supervision with mass supervision and government supervision with social supervision. At the same time, we should stand by the social forces to participate in the supervision work and bring the direct beneficiaries of post-disaster reconstruction into the supervision system, so that they can play an important role in evaluation and supervision, to achieve bottom-up coordination of supervision.
4) Rational decision-making shares rebuilding achievements: Decision-making mechanism concerns the overall situation is the main driving mechanism for the reconstruction project. The efficient and powerful decision-making command system in Wenchuan earthquake is an important factor for the great success of post-disaster reconstruction. Decision-making mechanism involves many factors such as participants, environment and implementation conditions. From the perspective of multiple-governance in post-disaster reconstruction, bounded rational decision-making is an inevitable choice.

To sum up, the government is undoubtedly in the leading position in the process of reconstruction after Wenchuan disaster, but it is not the only participant. Under the multiple-governance system, market participants, non-governmental organizations, residents of disaster areas and other social forces also are participants, so as to achieve collective wisdom, collective strategy and collective strength. In the whole reconstruction process, the participants coordinate and actively participate in each other to realize the benign cooperation mechanism among the participants, thus building a government-led, society-wide multiple-linkage and cooperation mechanism, which is the key to achieve high-quality, long-term stability and sustainability in disaster areas, and also to respond to future public crises. Emergency management puts forward reference value.

\section{The MeChanisM OF MUlTIPLE-PARTy COOPERATIVE CONSTRUCTION}

The urgency, disasters, uncertainties and complexity of disaster emergency management itself provide an opportunity for multiple-dimensional co-construction in disaster areas. Looking back on the reconstruction process of Wenchuan in 2008 , its multiple-linkage and co-construction system is the key factor to achieve great achievements in the reconstruction of disaster areas and plays an important role in the reconstruction process.

\section{A. Resource incentives}

The multiple-element co-construction system runs through the whole post-disaster reconstruction process. It has keen observation and mastery of all stages and key links of post-disaster reconstruction, and can use its flexible operation mechanism to coordinate the use of post-disaster reconstruction resources. The multiple-element co-construction system shows strong social strength, and has the strong material and human resources needed for reconstruction, which is the resource incentive for post-disaster reconstruction in Wenchuan [4]. On the one hand, multiple-participant activities among the whole people are manifested not only in the government's policy-driven implementation of the legal effect of post-disaster reconstruction projects, but also in the voluntary and non-profit nature of social organizations to meet the needs of the people and obtain the relevant needs of the people, at the same time, combine the needs of the victims, to achieve relief to guide development. The whole reconstruction system is the fundamental way to obtain resources for reconstruction. On the other hand, the multiple-stakeholders of the multiple-linkage co-construction mechanism and multiple-financing are the 
main supply force of post-disaster reconstruction funds and the cornerstone of post-disaster reconstruction projects. In a word, through the construction of multiple-linkage and co-construction mechanism, the team of post-disaster reconstruction can be strengthened in a relatively short time, and the resources of all parties can be widely collected.

\section{B. Power driven}

Earthquakes and other disasters are sudden, destructive and urgent. It's post-disaster reconstruction is an arduous practical project, focusing on anti-vulnerability construction in disaster areas. In this process, it is a powerful dynamic mechanism for post-disaster reconstruction in Wenchuan through a multiple-dimensional cooperative mechanism, linking forces from all walks of life, giving full play to their respective advantages, and actively and efficiently implementing reconstruction. The main manifestations are as follows: firstly, social organizations begin with the people, can quickly and sensitively invest in various reconstruction links, and can timely carry out psychological assistance and reconstruction of social relations for the victims, can actively mobilize professionals from all walks of life to join the reconstruction system, and better serve the disaster areas. secondly, in the multiple-joint construction system. thirdly, it can actively mobilize professionals from all walks of life to join the reconstruction system. The effective supervision and management and decision-making make the reconstruction process more sunny and fast, which is an important driving force for the sustainable development of the disaster area. Finally, the excellent traditional spirit of "one side is difficult, eight sides support" embodied in the multiple-dimensional cooperative construction mechanism in the disaster area enables the victims to be built physically and mentally, and stimulates the strength of the victims themselves. We should combine endogenous power with exogenous power to drive the better implementation of joint construction in disaster areas.

\section{CONCLUSION}

Practice has proved that the role of multiple-element co-construction mechanism in emergency management can not be ignored, and it is also an innovation of the new governance pattern of co-construction, co-governance and sharing in the new era. However, the positive effect of multiple-linkage and co-construction mechanism needs the joint efforts of government, market, society and individual citizens. the following enlightenment can be drawn through summing up the experience of Co-construction of Wenchuan reconstruction.

\section{A. Strengthen the concept of disaster prevention and mitigation among the public}

People's self-rescue and mutual rescue are the basis of relief When disaster comes [5]. We should strengthen people's awareness of disaster prevention and mitigation in disaster-stricken areas. we should face up to its essence and try our best to understand and learn relevant knowledge so as to fundamentally reduce the damage caused by disasters starting from the disaster itself.

\section{B. Strengthening the Cultivation of Social Organizations}

Wenchuan reconstruction tells us the social organization have strength power from a new way. Social organization is an important part of the mechanism of multiple-linkage and co-construction, and a new subject of social governance pattern in the new era. In the process of post-disaster co-construction, the types of social organizations are diverse and complex, which also poses a certain challenge to the authority of the government and the sustainable development of the disaster-stricken areas [6]. Some measures should be taken to strengthen the management and rational mobilization of social organizations so as to become a strong reserve force of the government under the multiple-governance system.

\section{REFERENCES}

[1] X. Yunxing, L. Chunyan. The Predicament of "Justice" in Government-led Post-disaster Reconstruction: A Case Study of Wenchuan 5.12 Earthquake[J].Journal of Guizhou Normal University (Social Science Edition),2018(06):70-76. (In Chinese)

[2] Y. Hongguang. Shandong Province promulgated Measures to support the recovery and reconstruction of disaster areas[J].Rural know all,2018(21):16. (In Chinese)

[3] L. Xia. Research on Social Organization Intervention in Community Reconstruction after Disaster: A Case Study of Lushan Earthquake[J].Decision consultation,2018(05):80-82. (In Chinese)

[4] D. Wenwen. Summary of Social Organizations Participating in Post-disaster Community Governance[J].Southern China,2018(09):48-49+59. (In Chinese)

[5] Q. Yongan, G. Linsheng. Beichuan Road for Ten-Year Post-Wenchuan Earthquake Reconstruction and Development and Thoughts on Disaster Prevention and Mitigation in the New Era (2)[J]. City and disaster reduction, 2018(04):40-47. (In Chinese)

[6] L. Zhihui. Ya'an Practice of Cooperating Social Forces to Participate in Disaster Relief and Reconstruction[J].SME Management and Science and Technology (Mid-term Journal),2016(03):131-132. (In Chinese) 